\title{
La Suprema Corte de Justicia y el rescate comunicativo del Estado Nación: el caso de la Ley Televisa
}

\author{
Javier Esteinou Madrid* \\ Universidad Autónoma Metropolitana, \\ UNIDAD XOCHIMILCO
}

Con la valiente resolución jurídica que tomó la Suprema Corte de Justicia de la Nación al declarar inconstitucional la Ley Televisa presenciamos un evento de enorme trascendencia histórica que contribuyó significativamente a recolocar nuevamente a principios del nuevo milenio al Estado nación como instancia rectora de proceso de comunicación del país frente a las fuerzas monopólicas de la posmodernidad tecnológica y política. De esta forma, a partir de los fundamentos constitucionales la Corte se enfrentó con firmeza y soberanía a los poderes fácticos informativos que habían erosionado drásticamente la esencia, la soberanía, la centralidad, y la misión del Estado mexicano como cerebro dirigente de la comunidad al finalizar el siglo xx y comienzos del siglo xxI y reivindicó el sentido fundamental de la existencia y acción del Estado en el proceso de construcción del proyecto de comunicación colectivo desde los postulados nacionalistas de la Constitución Mexicana.

* Doctor en Sociología, (Facultad de Ciencias Políticas y Sociales, Universidad Nacional Autónoma de México), Maestro en Sociología, (Departamento de Sociología y Ciencias Políticas y Sociales, Universidad Iberoamericana), Licenciado en Ciencias y Técnicas de la Información, (Departamento de Comunicación, Universidad Iberoamericana), Estudios de Filosofía, (Instituto Superior de Estudios Filosóficos). Investigador Titular del Departamento de Educación y Comunicación de la Universidad Autónoma Metropolitana Unidad Xochimilco, México, D.F. Autor de diversos textos. Ex Vicepresidente (Fundador), Asociación Mexicana de Investigadores de la Comunicación (AMIC), México D.F, (1981-1983). Ex Vicepresidente, Asociación Latinoamericana de Investigadores de la Comunicación (ALAIC), Florianópolis, Brasil, (octubre de 1989 a octubre de 1992). Ex Vicepresidente Regional, Federación de Facultades de Comunicación en América Latina (felafacs), Colombia, (1958- 1998). Premio Nacional de Periodismo 2004, Club de Periodistas de la Ciudad de México A.C., México, D.F, diciembre del 2004. Correo electrónico: jesteinou@gmail.com 
Es por ello, que si los magistrados de la Corte con su comportamiento institucional ya comprobaron que "estaban hechos" de moralidad, civilidad, imparcialidad y constitucionalismo para realizar su deliberación autónoma frente a las presiones que ejercieron los promotores de la Ley Televisa; ahora el Poder Ejecutivo y el Poder Legislativo deben demostrar públicamente al país si están hechos de equidad, justicia y republicanismo elemental para crear una nueva Ley Federal de Radio y Televisión y de Telecomunicaciones que permita el impulso a la democracia, la pluralidad y el crecimiento comunicativo colectivo equilibrado en nuestra nación.

Palabras clave: Democracia comunicativa, Suprema Corte de Justicia de la Nación, Estado nación comunicativo, Ley Televisa, Transición comunicativa, violaciones constitucionales, Nuevo modelo de comunicación.

With the brave legal resolution taken by the Justice Supreme Court of the Nation, which declared inconstitutional the Televisa Law, we are witnessing a fact of huge historical importance which contributed to replace again, at the beginning of the new milenium, the nation State as a governing agent of the communication process in the country which faces the monopolic forces of the technological and political posmodernity. Therefore, from the constitutional bases, the Court faced firmly and with sovereignty the factical informative powers which have eroded drastically the esence, the sovereignty, the centrality, and the mission of the Mexican State as community ruler brain at the end of the XX century and the beginning of the $X X I$ century, and vindicated the fundamental sense of State existence and of action in the process of construction of the colective communicational project from the nationalist postulates of the Mexican Constitution.

For that reason, the Court magistrates have proved, with their institutional behavior, that they "are made" of morality, civility, impartiality and constitutionalism to develop their autonomous deliberation in relation to the pressures put by promoters of the Televisa Law. But now the Executive and the Legislative Powers must publicly show to the country if they are made of justice and elemental republicanism to create a new Telecommunications, Television and Radio Federal Law which alows the impulse of democracy, plurality and a balanced colective communicative growth in our nation.

Key words: Communicative democracy, Nation Supreme Court of Justice, Communicative Nation State, Televisa Law, Communicative transition, constitutional violations, New model of communication. 
El 1 de diciembre del 2005 se aprobó obscuramente en la Cámara de Diputados, vía fast track, un proyecto de Reforma a la Ley Federal de Radio y Televisión (LFRYTV) y a la Ley Federal de Telecomunicaciones (LFT) denominada Ley Televisa que fue presentada y dictaminada en 8 días, apoyada por la unanimidad de 327 diputados, aprobada en 7 minutos, sin mociones a favor o en contra, ni abstenciones y sin destacar la trascendencia de la misma (Calleja, 2005; Islas, 2005; Carriedo, 2005; Trejo, 2005). Posteriormente, el 30 de marzo del 2006 un sector mayoritario de legisladores a favor de la Ley Televisa aprobaron descaradamente el mismo proyecto de reforma en el Senado de la República por 81 votos a favor, 40 en contra y 4 abstenciones, (El Universal, 31 marzo 2006) sin ninguna modificación sustancial o cirugía mayor (El Universal, 24 febrero 2006), ni discusión alguna a las severas intervenciones en contra que presentaron los legisladores de oposición que la cuestionaron profundamente.

El momento y la forma silenciosa en el que se presentó dicha propuesta de modificación a la LFRyTV, fue estratégicamente pensada y calculada por los grandes monopolios mediáticos que crearon e impulsaron anónima y subrepticiamente dicha reforma, pues eligieron la fase más vulnerable del sistema político nacional para presionar que las fuerzas políticas la aprobaran: La etapa electoral. Así, se eligió el frágil periodo de elecciones del 2006 donde ninguno de los candidatos políticos en contienda y los partidos políticos, se encontraban en condiciones de fuerza para oponerse a la misma, pues el costo institucional de enfrentarse a los enormes poderes mediáticos fácticos implicaría poner en riesgo la realización exitosa de sus campañas para la Presidencia de la República y al Congreso de la Unión, ya que el éxito de dichos procesos dependían totalmente del acceso a los medios de información colectivos, especialmente privados.

En este sentido, todos los partidos políticos, los candidatos, el Presidente, los Poderes Públicos, los secretarios de Estado, los órganos de gobierno, etc. sabían claramente que dicha propuesta era una ley desigual, marginadora, injusta, abusiva, excesiva, etc, que la preparó la empresa Televisa y la negoció con las cúpulas partidistas para favorecer desproporcionadamente sus intereses de largo plazo en el país; pero asombrosamente todos los sectores la aceptaron, directa o indirectamente, argumentando que en la fase del proceso electoral no podían enfrentar a los enormes poderes mediáticos, pues el costo sería desastroso para su éxito político.

La Suprema Corte de Justicia y el rescate comunicativo • 6I del Estado Nación: el caso de la Ley Televisa 
Para legitimar y acelerar la aceptación de este abrupto y sospechoso proceso legislativo las fracciones parlamentarias que aprobaron la iniciativa, argumentaron que el Congreso debía adelantarse rápidamente a futuras presiones con la elaboración de una nueva propuesta jurídica que evitara que los compromisos políticos contraídos por el Poder Ejecutivo otorgara discrecionalmente nuevas concesiones de radio y televisión a grupos económicos muy poderosos antes que terminara el gobierno del Presidente Vicente Fox en diciembre del 2006 (Islas, 2005).

De esta forma, siendo que en el intento legislativo inicial realizado en el Senado de la República, durante 2003 al 2005, a través de la Iniciativa de Reforma Integral de la Ley Federal de Radio y Televisión, Televisa no logró que sus propuestas para la transformación de la radiodifusión nacional fueran aceptadas automática y literalmente, se llevó su proyecto de reforma a la Cámara de Diputados, y obtuvo todo lo que pidió, sin nada a cambio para la sociedad, sólo paz y armonía para los candidatos a la Presidencia de la República (El Universal, 26 enero 2006).

Asombrosamente, después de haber sido aprobada y enviada la Ley Televisa al Senado de la República para su revisión, Pablo Gómez, coordinador de la bancada del Partido de la Revolución Democrática (PRD) en la Cámara de Diputados; Leonel Cota, Presidente del Partido; e Inti Muñoz, vocero del PRD en San Lázaro; confesaron públicamente que estaban muy arrepentidos y avergonzados por haber admitido la Minuta. Así, "sin haber leído el texto del proyecto, Pablo Gómez pidió al resto de su partido que la aprobaran por considerarla benéfica para el país. Lo hicieron y junto con las otras bancadas aprobaron, sin leer ni entender, una propuesta de ley que hoy es sinónimo de traición a los electores que les dieron su voto y su confianza, y que en cualquier otro país tendrían gravísimas consecuencias para ellos y sus intereses" (Infosel Financiero, 28 marzo 2006).

La aprobación incondicional bajo presiones electoreras de la Ley Televisa por la mayoría de miembros en la Cámara Alta y la Cámara Baja en el Congreso de la Unión que estuvieron sometidos a fuertes presiones por parte de los monopolios televisivos, significó la rendición y el sometimiento del Estado mexicano para defender los intereses nacionales ante el avasallante poder privado comercial de las televisoras monopólicas organizadas. De esta forma, el Estado perdió su capacidad rectora y su soberanía para dictar las directrices de las políticas públicas que debe seguir el proyecto de desarrollo comunicativo de nuestra nación y se subordinó a los restringidos intereses particulares del programa de telecomunicaciones del gran capital monopólico (Infosel Financiero, 1 marzo 2006).

62 - Javier Esteinou Madrid 
Haciendo caso omiso de las numerosas peticiones de los múltiples grupos sociales que demandaron que el Poder Ejecutivo vetara la Ley Televisa por conllevar múltiples irregularidades, en base a su facultad de veto, y sin considerar los grandes errores y violaciones constitucionales que conllevó dicha propuesta; asombrosamente el Presidente Vicente Fox, publicó el 11 de abril del 2006 en el Diario Oficial de la Federación la nueva LFRytv y la LFT para darle su reconocimiento oficial y colocarla en plena vigencia jurídica. De esta forma, siguiendo la misma estrategia que adoptaron los gobiernos prístas durante muchas décadas anteriores al aprovechar la "Semana Santa" como momento protegido para anunciar las fuertes devaluaciones del peso, se utilizó este mismos período vacacional donde la población se encontraba muy distraída por el descanso y la celebración de las ceremonias religiosas, para publicar dicha Ley (El Universal, 9 abril 2006).

Así, el Poder Ejecutivo desconoció el mandato de la Constitución Política Mexicana que señala que la Consejería Jurídica de la Presidencia de la República debía formular observaciones a las propuestas de normatividades que le son enviadas por el Congreso de la Unión para su autorización, y sin realizar dicho procedimiento institucional propagó oficialmente dicha ley para que entrara en vigencia lo antes posible, incluso antes de que concluyera el periodo reglamentario que le correspondía cumplir para efectuarla (La Jornada, 10 mayo 2006).

Con ello, el Presidente Fox demostró nítidamente, una vez más, que la tendencia que siguió en materia de comunicación social a lo largo de todo su sexenio fue modificar desde "el inicio de su mandato la otrora relación de superioridad en la que la televisión estaba al servicio del presidente; para ahora "modernizarla" y ponerse él y su gabinete como instrumentos al servicio de las televisoras" (Corral, 2006-C). Con la autorización de este supuesto avance jurídico lo que el Presidente Vicente Fox Quezada hizo, fue exactamente "lo mismo que realizó el Presidente Adolfo López Mateos hace 46 años: publicar la reforma legal de la radio y la televisión que a su modo y conveniencia elaboró la entonces naciente Cámara Nacional de la Industria de la Radio y la Televisión (CIRT), pero ahora con una diferencia sustancial: la Ley de hace más de 4 décadas, se elaboró bajo un acuerdo donde participaron radiodifusores y la emergente televisión mexicana; y ahora fue una sola empresa dominante la que la elaboró: Televisa (Corral, 2006-C).

\section{La Suprema Corte de Justicia y el rescate comunicativo $\bullet 63$ del Estado Nación: el caso de la Ley Televisa}


Después de haber sido aprobadas por la Cámara Alta y la Cámara Baja del Congreso de la Unión y posteriormente a ser publicadas por el Ejecutivo Federal en el Diario Oficial de la Federación las Reformas las Leyes Federales de Radio y Televisión y de Telecomunicaciones el 11 de abril del 2006, un grupo plural de 47 senadores disidentes de todos los partidos, encabezados por los senadores Javier Corral Jurado del PAN, Manuel Barlett Díaz del PRI y César Raúl Ojeda Zubieta del PRD, iniciaron el 4 de mayo del 2006 una Acción de Inconstitucionalidad sobre dichas normas ante la Suprema Corte de Justicia, con el fin de solicitar su anulación por ser violatorias de la Constitución Mexicana y contener un conjunto de aberraciones y disposiciones jurídicas contrarias al interés público (El Universal, 17 abril 2006).

Esta impugnación ante el Poder Judicial fue un hecho histórico en la vida del Congreso de la Unión, pues desde que se reformó el artículo 105 de la Constitución Política Mexicana para crear la Controversia y la Acción de Inconstitucionalidad, esta fue la primera ocasión en que se ejerció tal impugnación, con apoyo del $36.7 \%$ de los representantes de cuatro partidos del Senado de la República, esto es, estuvo representada por 29 entidades de las 32 que componen el pacto federal (El Universal, 9 mayo 2006). Así, esta fue la primera vez que una parte del Congreso demandó jurídicamente a otra parte del Congreso por violar flagrantemente la Constitución al aprobar ilegalmente reformas a la Ley Federal de Radio y Televisión y la Ley Federal de Telecomunicaciones para beneficiar expresamente a los dos principales monopolios de televisión privada en el país, en perjurio del resto de la sociedad (La Jornada, 4 mayo 2006).

Dicha Acción de Inconstitucionalidad estuvo apoyada simultáneamente, entre otros, por más de la tercera parte de los miembros del Senado de la República (15 senadores del PRI, 16 del PAN, 15 del PRD y 1 de Convergencia) (La Jornada, 4 mayo 2006), por 110 diputados del PRI y del PRD (Reforma, 30 abril 2006), el Alto Comisionado de la Organización de las Naciones Unidas (Milenio, 30 abril 2006), la Asociación de Autoridades Locales de México (AALMAC) (El Universal, 7 mayo 2006), Fuerza Ciudadana A.C. (El Universal, 7 mayo 2006), el Frente Nacional Ciudadano de Rechazo a la "Ley Televisa", y por diversas Organizaciones No Gubernamentales (ONGs) y movimientos sociales (El Universal, 5 de mayo 2006).

64. Javier Esteinou Madrid 
La solicitud de suspensión legal de la Ley Televisa, a través de la Acción de Inconstitucionalidad no fue dirigida contra las empresas de televisión que la respaldaron, sino contra el Poder Legislativo y el Poder Ejecutivo de la Federación que con su complicidad las aprobaron como el mayor plan de negocios de las televisoras privadas y les dieron valor oficial para entrar en vigor rápidamente antes de vencer los plazos oficiales establecidos (Corral, 2006-A). Los fundamentos de dicha Acción de Inconstitucionalidad no se basaron en tesis políticas, sociales, o ideológicas, sino en argumentaciones rigurosamente jurídicas que denunciaron, por una parte, lo viciado, mañoso, arbitrario, ilegal y desaseado del procedimiento legal que se adoptó para aprobar la ley; y por otra, en las 21 violaciones flagrantes de 27 artículos de la Constitución Política Mexicana que produjo tal normatividad (El Universal, 4 mayo 2006).

Con esta impugnación jurídica histórica por legisladores disidentes se inició en el 2006 un análisis riguroso por parte de la Suprema Corte de Justicia de la Nación que le devolvería a la sociedad, un año después, su proyecto de comunicación expropiado, la restauración de la división de poderes públicos republicanos, la rectoría del Estado en materia de comunicación, el rescate de las bases del Estado Nación a partir de los principios vertebrales de la Constitución de 1917 y la creación de cimientos sólidos para la transición a la democracia comunicativa en el país que estaba paralizada.

\section{LA REIVINDICACIÓN JURÍDICO POLÍTICA DEL ESTADO MEXICANO}

Después de haberse aprobado la Ley Televisa por el Poder Ejecutivo y el Poder Legislativo durante más de un año, fue sólo el Poder Judicial de la Federación el que cobró conciencia del gravísimo error cometido por los dos poderes públicos anteriores y detuvo el avance de dicha normatividad anticonstitucional a través de la rigurosa aplicación de la filosofía de la Constitución Mexicana. Así, fue el 7 de junio del 2007, fecha de la conmemoración del Día de la Libertad de Prensa, y por lo tanto, del impulso de la libertad del espíritu humano por encima de las fuerzas de la asfixia del poder, cuando el Poder Judicial de la Federación a través de la Suprema Corte de Justicia de la Nación anuló los aspectos centrales de la Ley Televisa y colocó el mandato de la Constitución Mexicana por encima de los intereses de los poderes fácticos informativos que ya la habían rebasado con exceso, cinismo, impunidad y prepotencia desde hace varias décadas.

\section{La Suprema Corte de Justicia y el rescate comunicativo $\bullet 65$ del Estado Nación: el caso de la Ley Televisa}


Con a la demanda de Acción de Inconstitucionalidad exigida por el grupo de legisladores de oposición y su respaldo social correspondiente que la inscribieron ante el Poder Judicial de la Federación para solicitar la anulación de la Ley Televisa; la Suprema Corte de Justicia evitó someterse a las presiones políticas que ejercieron los poderes fácticos comunicativos, particularmente electrónicos, sobre dicha institución, para evitar que esta normatividad fuera anulada por los magistrados (El Universal, 8 mayo 2006). Así, contrariamente a la actitud claudicante que tuvieron el Poder Legislativo y el Poder Ejecutivo al someterse a los chantajes e inhibiciones del gran poder mediático, especialmente de las televisoras comerciales privadas, para renunciara a su autonomía de poderes republicanos y ceder apoyando contundentemente la aceptación oficial de la Ley Televisa; la Suprema Corte actuó con coraje y vocación de poder republicano independiente y decidió imponer los principios constitucionales básicos sobre los apetitos monopólicos de los poderes mediáticos en el terreno comunicativo.

A diferencia de la dinámica política del Poder Legislativo y del Poder Ejecutivo que estuvieron íntimamente ligados con los "intereses" del proceso electoral o las gestiones cotidianas del gobierno que los convirtió en instituciones muy endebles para enfrentar las imposiciones de los monopolios informativos, obligándolos a pagar altos costos para lograr su gobernabilidad; la vida del Poder Judicial no estuvo vinculada directamente con dichos "intereses", lo cual le permitió mayor independencia para actuar con ética y valor republicano para rechazar la Ley Televisa (El Financiero, 5 mayo 2006). Es decir, debido a que afortunadamente los ministros de la Corte decidieron no vivir en campañas personales, ni sujetos a la dictadura del spot para obtener legitimidad, ni luchar por intereses políticos particulares, ni enredarse en disputas electorales para ratificar sus cargos, ni ser entrevistados todos los días por las televisoras para posicionarse profesionalmente, ni se preocuparon por aparecer en espacios mediáticos de "éxito" coyuntural, etc, mientras examinaban y dictaminaban la Acción de Inconstitucionalidad; ellos construyeron condiciones de limpieza y fortaleza institucional para encarar con solidez los chantajes, la intimidación y los intentos de corrupción que se vertieron sobre sus personas. De esta manera, al solamente preocuparles a los magistrados la aplicación de los principios de la Constitución Política Mexicana, éstos pudieron ejercer ética, honrosa, moral y profesionalmente su responsabilidad de poder republicano soberano para aplicar con integridad la justicia constitucional, sin que ningún poder fáctico amoral supra estatal se los obstruyera.

66- Javier Esteinou Madrid 
Sin embargo, no obstante esta situación de relativo blindaje institucional con que contaron los miembros de la Suprema Corte de Justicia de la Nación durante el proceso de análisis que realizó para normar su juicio sobre la inconstitucionalidad o no de la Ley Televisa en mayo del 2007; este poder republicano sufrió diversas presiones a través de los medios televisivos, radiofónicos y escritos para evitar que el Poder Judicial ejerciera justicia en el terreno comunicativo (Vértigo No. 322, 2007).

Ante esta circunstancia de intimidación monopólica el ministro de la Corte, Sergio Salvador Aguirre Anguiano, declaró al inicio del proceso de reflexión jurídica que la Suprema Corte no se dejaría presionar por persona o institución alguna. Ni por los sectores a favor de que pretendían que se aprobara la ley en cuestión, que influenciaron argumentando "que de resolver la Corte el tema de entidades desconcentradas, conforme al último precedente, habría una regresión innegable hacia el autoritarismo, o que de dictaminar como lo solicitaron los accionantes se frenaría el desarrollo tecnológico y comercial de la radio, la televisión y otras telecomunicaciones, etc. Ni tampoco concedería afectarse por los grupos en contra de que se legalizara la ley, que fundamentaron sus presiones sosteniendo que si no se resolvía la inconstitucionalidad de las leyes impugnadas provocaría que el partido político dominante que afirmó lo primero no colaborase en los quehaceres propios de la reforma del Estado. Que la Corte puede legislar, pero que de persistir en esa posición, se reformaría la Constitución, para que en lo sucesivo no pudiera hacerlo igual. Que de no resolver como lo solicitaron los accionantes se establecería a perpetuidad un duopolio televisivo, etc" (Acción de inconstitucionalidad ..., 2007).

En este marco de presiones el magistrado Aguirre Anguiano recalcó que "no saben de lo que estamos hechos los ministros para cumplir con nuestras encomiendas. No pagamos costo político alguno. Estamos prestos a realizarlas, a desahogarlas sin ideologización, ni politización partidista, simplemente conforme a nuestra convicción, imparcialmente, sin estridencias, tal y como está previsto en la Constitución, sin preocupaciones de otras políticas. Esa será nuestra única ocupación, no nos preocupan otras consecuencias en corto plazo y a la larga. Como Tribunal Constitucional que somos, sabemos que la primacía de la Constitución es lo más rentable para nuestro país" (Acción de inconstitucionalidad..., 2007).

Como complemento a dicha posición ético profesional de los Jueces, el ministro Aguirre Anguiano, para evitar confusiones sobre el campo de reflexión, deliberación y responsabilidades de los magistrados del máximo tribunal de

\section{La Suprema Corte de Justicia y el rescate comunicativo $\bullet 67$ del Estado Nación: el caso de la Ley Televisa}


justicia sobre la Acción de Inconstitucionalidad, delimitó desde el inicio de los trabajos la naturaleza del problema señalando los límites de lo que si les correspondía abordar como jueces y los aspectos que no les toca revisar, ni decidir como magistrados. Al respecto señaló "que la Acción de Inconstitucionalidad no se trata de los aspectos técnicos de la convergencia tecnológica; tampoco se trata de los avances o beneficios de la tecnología digital respecto a la analógica; no tiene que ver con el ancho de banda de frecuencia; no tiene que ver con el desarrollo tecnológico de los proveedores o prestadores de los servicios, sean estos de radiodifusión o de telecomunicaciones; no resolveremos sobre la competitividad a nivel nacional o internacional de los servicios de telecomunicaciones; menos aún nos pronunciaremos respecto a las características técnicas de los servicios que prestan los concesionarios en materia de radio, televisión y telecomunicaciones" (Acción de inconstitucionalidad ..., 2007).

De lo que si se trató y en eso residió la responsabilidad exclusiva de la Suprema Corte de Justicia fue de "precisar qué constituye la propiedad originaria del Estado mexicano, es decir, de qué es dueño el Estado. De establecer si el espectro radioeléctrico es un bien del dominio público. De precisar el régimen constitucional de las concesiones públicas. De delimitar la manera en que constitucionalmente los bienes o servicios públicos son concesionados. De decidir si una concesión puede ser desvinculada de un uso determinado y específico del bien de dominio público sobre el cual fue otorgada. Se trata en suma, de determinar si la ley impugnada específicamente, en relación a algunos de los artículos del decreto que la modificó, respetan o no los principios constitucionales de equidad, no discriminación, concurrencia económica y rectoría del Estado (Acción de inconstitucionalidad..., 2007).

Con la aplicación de dichos criterios ético profesionales como marco del comportamiento de los magistrados y con el dictamen crítico de inicio, la Corte colocó las bases mínimas para poder actuar como un poder republicano independiente, transparente, honesto, equilibrado y moral que buscó aplicar la justicia en esta materia y no defender intereses privilegiados de grupos, especialmente monopólicos. Después de trabajar en 11 sesiones colectivas los 9 ministros concluyeron el 7 de junio del 2007 la siguiente sentencia definitiva:

Primero.- Fue procedente y parcialmente fundada la Acción de Inconstitucionalidad.

Segundo.- Se declaró la validez de los artículos Segundo, Cuarto y Quinto

Transitorios; 9-A, primer párrafo y fracciones XI, XII, XIV, y XVI; 9-D de la Ley Federal de Telecomunicaciones, y de los artículos Segundo Transitorio; 16 por lo 
que hace al mecanismo de refrendo; 17-E, 17-F, 17-G,20,21-A y 79-A, fracción Ia de la Ley Federal de Radio y Televisión en términos de lo expuesto en los considerándoos Quinto a Décimo Segundo de la presente ejecutoria.

Tercero.- Se declaró la invalidez de los artículos 9-C de la Ley Federal de Telecomunicaciones y artículos 16 en la parte relativa al plazo de duración de las concesiones, 17 G, 28 y 28-A de la Ley Federal de Radio y Televisión en los términos precisados en los considerandos Décimo Tercero y Décimo Quinto, para los efectos señalados en el último considerando de este fallo.

Cuarto.- Fue fundada la omisión legislativa denunciada en términos del considerando Décimo Séptimo y para los efectos precisados en el último considerando de resolución" (Proyecto de resolución..., 2007).

Con dicha resolución de la Corte, se evitó que los poderes fácticos mediáticos suplantaran, subordinaran o rindieran al Poder Judicial y a su Suprema Corte de Justicia de la Nación, y permitieron que el Estado mexicano gobierne autónoma y soberanamente en el terreno de la aplicación de la justicia comunicativa para defender el interés público de la nación (La Jornada, 5 mayo 2006).

\section{EL SIGNIFICADO HISTÓRICO DE LA DECISIÓN}

DE LA SUPREMA CORTE DE JUSTICIA DE LA NACIÓN

Con la valiente resolución jurídica de la Suprema Corte no asistimos a un simple hecho coyuntural más de la burocracia legal del Poder Judicial de la Federación mediante la cual cotidianamente despacha innumerables asuntos legítimos de los ciudadanos en el país; sino presenciamos un evento de enorme trascendencia histórica que contribuyó significativamente a recolocar nuevamente a principios del tercer milenio al Estado nación como instancia rectora de proceso de comunicación del país frente a las fuerzas monopólicas de la posmodernidad tecnológica y política. De esta forma, a partir de los fundamentos constitucionales la Corte se enfrentó con firmeza y soberanía a los poderes fácticos informativos que habían erosionado drásticamente la esencia, la soberanía, la centralidad, y la misión del Estado mexicano como cerebro dirigente de la comunidad al finalizar el siglo xx y comienzos del siglo xxi y reivindicó el sentido fundamental de la existencia y acción del Estado en el proceso de construcción del proyecto de comunicación colectivo desde los postulados nacionalistas de la Constitución Mexicana.

Guardando toda proporción histórica, podríamos decir que la acción jurídico moral que ejecutó la Suprema Corte de Justicia en el terreno comunicativo fue

\section{La Suprema Corte de Justicia y el rescate comunicativo $\bullet 69$ del Estado Nación: el caso de la Ley Televisa}


un acto equivalente al que en el siglo XVIII ejerció el libertador Benito Juárez, cuando el 12 de julio de 1859 decretó las Leyes de Reforma para limitar el enorme poder ideológico político que alcanzó la iglesia como poder fáctico al obstaculizar el proceso democratizador de la comunidad nacional en esa época; y permitió el avance del proyecto de la República Federal como instancia suprema para dirigir y defender a la sociedad mexicana ante las presiones de dominio que intentaban imponer las fuerzas coloniales (Zoraida Vásquez, 2006).

En este sentido, ante el deplorable ejemplo histórico que dejó el comportamiento del Poder Ejecutivo y de la mayoría de los representantes del Poder Legislativo al aprobar de manera irresponsable, mańosa, condicionada y viciada la Ley Televisa en el año 2005 en la Cámara de Diputados y en marzo del 2006 en la Cámara de Senadores, y posteriormente aceptarse en abril del mismo año por el Poder Ejecutivo; el Poder Judicial de la Federación, dio un ejemplo clásico de responsabilidad, de profesionalismo, de nacionalismo y de ética institucional al demostrar cómo un poder republicano del Estado mexicano se debe comportar con soberanía, autonomía, dignidad e independencia frente a las fuertes presiones de los grandes monopolios mediáticos que buscaban proteger sus intereses de expansión oligopólica, para salvaguardar las necesidades comunicativas de la mayoría de la población.

Con el fallo jurídico de la Corte vivimos un verdadero proceso histórico de separación de poderes republicanos, pues mientras dos de los poderes públicos, el Legislativo y Ejecutivo, ya se habían rendido ante los apetitos voraces de los grandes poderes fácticos informativos entregando la autonomía del Estado a la dinámica de los caprichos del mercado salvaje desregulado; el Poder Judicial, actuó como un poder republicano independiente frente a los otros dos poderes subordinados y frenó la propuesta de los monopolios de la difusión comercial y reencausó el proyecto comunicativo de la sociedad mexicana dentro la lógica de la figura histórica de la República para ubicar los principios constitucionales por encima de la dinámica de la Mano Invisible del Mercado en el terreno de las comunicaciones nacionales.

Evitando la actitud vergonzosa que mantuvieron el Poder Legislativo y el Poder Ejecutivo en el 2005 y en el 2006 para fortalecer el modelo del antiguo Estado Padrastro Comunicativo en el campo de la comunicación al no discutir y modificar la propuesta de la Ley Televisa en el Congreso y aprobarla intacta, subordinándose incondicionalmente a los intereses de la expansión monopólica de los sectores informativos; la Suprema Corte de Justicia actuó como un poder republicano autónomo. De esta forma, no se rindió ante las fuertes presiones de

$70 \cdot$ Javier Esteinou Madrid 
los poderes fácticos mediáticos y optó por rescatar el modelo del Estado Nación para defender a partir del espíritu de la Constitución Mexicana las garantías comunicacionales básicas de la mayoría de los ciudadanos olvidados desde hace varias décadas por la dinámica desaforada del mercado salvaje.

Así, mientras los poderes Legislativo y Ejecutivo crearon las condiciones jurídico políticas para el crecimiento superlativo de los macro poderes salvajes comunicativos que fortalecerían la dinámica del Estado Padrastro que no defendió el interés colectivo y la esencia de la República; la Suprema Corte de la Justicia, como poder independiente, colocó las bases constitucionales para el rescate filosófico, conceptual, jurídico, político e histórico del Estado Nación en materia de comunicación social y ofreció un panorama de futuro cultural más equilibrado para el porvenir armónico del país.

En este sentido, podemos decir que la acción de la Suprema Corte de Justicia recobró la médula comunicativa del Estado Nación mexicano de las garras del Estado Padrastro que lo tuvo secuestrado y olvidado durante varias décadas a través de la imposición de los intereses comunicativos particulares de los grandes monopolios de la radiodifusión sobre los requerimientos informativos mínimos de la sociedad mexicana. Con ello, la Corte evitó que continuara siendo el Estado Padrastro la cabeza que se apoderara de la administración del espectro radioeléctrico para subordinar a la sociedad a las necesidades irrefrenables del mercado comunicativo desbocado de los monopolios de la información y no para impulsar su desarrollo comunicativo elemental.

De esta manera, la Suprema Corte de Justicia actuó como un poder público soberano que defendió el interés social de la nación y la esencia republicana del Estado mexicano por sobre las exigencias de protección y legitimación de los requerimientos económicos y políticos de los oligopolios informativos que ya habían avanzado mucho en el campo comunicativo al crear en las últimas décadas la fórmula del Estado Cero en México, que planteó que para ser modernos, cada vez, había que tener menos Estado rector de las comunicaciones y entregar progresivamente el modelo y el proceso de la comunicación nacional a la dinámica del mercado salvaje desregulado. Así, con su acción pulcra de poder soberano la Corte rescató la filosofía básica de la Constitución Política Mexicana en el ámbito comunicacional y con esta óptica colocó en su lugar histórico las piezas fundamentales de la estructura comunicativa del Estado nación y de la República que paradójicamente se habían desarticulado, extraviado y hasta abortado en el régimen de la "transición pacífica a la democracia” del 2000 al 2006 dirigido por el ex presidente Vicente Fox

\section{La Suprema Corte de Justicia y el rescate comunicativo • 7 I del Estado Nación: el caso de la Ley Televisa}


Q. y que se heredaron directamente al nuevo régimen político del Felipe Calderón del 2006 al 2012.

De aquí, la importancia trascendental de la acción sabia y equilibrada que tomó la Suprema Corte de Justicia de la Nación ante esta deliberación histórica en el terreno comunicativo, cultural, político, económico y democrático del país, pues con su decisión se canceló el proyecto injusto de la mega privatización, la concentración monopólica y el despojo al Estado del espectro radioeléctrico que es patrimonio de la nación para poder interactuar colectivamente y sobrevivir. Con ello, la Corte rescató las bases jurídico-morales constitucionales para recimentar al Estado nación mexicano en el ámbito comunicativo y cultural que a principios del siglo XXI se encontraba en una fuerte fase de crisis de soberanía, legitimidad y rectoría nacional en la etapa de la posmodernidad planetaria.

De esta manera, la intervención de la Suprema Corte corrigió la enorme tendencia errática que autorizaron dos poderes públicos de la República rendidos a los monopolios mediáticos que pretendieron introducir un futuro comunicativo autoritario, asfixiante, sometido, excluyente e inhumano; y colocó los límites constitucionales mínimos para que la comunidad nacional pudiera generar otro futuro participativo, democrático, plural, incluyente y humano para el crecimiento comunicativo integral de la sociedad mexicana en el siglo XXI.

En síntesis, con su acción imparcial y justa la Suprema Corte de Justicia colaboró, por un lado, a recobrar la fuerza moral y ejecutiva de los Poderes Públicos Republicanos que paulatinamente se erosionaron en México, y con ello, estableció los cimientos del "Estado de Derecho Comunicativo”; y por otra, aportó bases civilizatorias fundamentales para que la sociedad mexicana conviva en condiciones de justicia, armonía e igualdad para propiciar la transición pacífica a la democracia comunicativa al inicio del nuevo milenio en México.

\section{CaraCterísticas de LA ACTUACIÓN DE LA CORTE}

La acción que realizó la Suprema Corte de Justicia de la Nación en junio del 2007 como poder republicano responsable para definir la Acción de Inconstitucionalidad sobre la Ley Televisa, fue un proceso histórico ejemplar para la sociedad mexicana, pues tuvo, entre otras, las siguientes 8 características institucionales:

1. Desde el inicio del proceso jurídico la Suprema Corte definió públicamente su posición como Poder republicano autónomo e independiente señalando que no actuaría bajo inhibiciones de ningún sector, ni de los impugnadores,

\section{$72 \cdot$ Javier Esteinou Madrid}


ni los defensores de la Ley Televisa; y demostró a lo largo de toda su actuación jurídica su ubicación valiente que no se amedrentó frente a las fuertes presiones de calumnia, desprestigio, manipulación y desinformación que ejerció el poder fáctico mediático, especialmente, a través de Televisa y Televisión Azteca. Durante este periodo fue clara la fuerte presión mediática ejercida por las televisoras y otros medios escritos sobre los ministros de la Corte, particularmente, sobre el ministro ponente Sergio Salvador Aguirre Anguiano, y algunos de los cerebros responsables de la Acción de Inconstitucionalidad contra la Ley Televisa, como fueron los ex senadores Javier Corral Jurado y Manuel Bartlett Díaz.

2. Contrastando con los marcos de actuación confusa y manipuladora de la mayoría de los representantes del Poder Legislativo cuando aprobaron la Ley Televisa en el Congreso de la Unión, la Corte formuló desde el principio de sus trabajos que sus fundamentos de actuación serían "determinar qué constituye la propiedad originaria del Estado mexicano, es decir, de qué es dueño el Estado. De establecer si el espectro radioeléctrico es un bien del dominio público. De precisar el régimen constitucional de las concesiones públicas. De delimitar la manera en que constitucionalmente los bienes o servicios públicos son concesionados. De decidir si una concesión puede ser desvinculada de un uso determinado y específico del bien de dominio público sobre el cual fue otorgada. Se trató en suma, de determinar si la ley impugnada específicamente, en relación a algunos de los artículos del decreto que la modificó, respetaban o no los principios constitucionales de equidad, no discriminación, concurrencia económica y rectoría del Estado mexicano (Acción de inconstitucionalidad..., 2007).

3. Fue un poder republicano que desde el inicio se comportó con transparencia institucional pues, por una parte, dio a conocer a la sociedad con anticipación a que se iniciaran las discusiones y deliberaciones de los 9 ministros el dictamen que presentó el ministro ponente Sergio Salvador Aguirre Anguiano sobre la Acción de Inconstitucionalidad de la Ley Televisa, vía la página Web de la Suprema Corte, para que la opinión pública estuviera informada sobre el hecho que se iba a dictaminar. Por otra parte, a diferencia del Poder Legislativo y del Poder Ejecutivo que no difundieron ampliamente las reuniones para discutir la Iniciativa de Ley sobre la Reforma a la Ley Federal de Radio Televisión y la Ley Federal de Telecomunicaciones durante el años 2005 y 2006; la Suprema Corte diseminó ampliamente a la sociedad todas sus sesiones a través del Canal de Televisión de la Suprema Corte de Justicia, el Canal de Televisión del Congreso de la Unión y 700 sistemas de televisión por cable.

\section{La Suprema Corte de Justicia y el rescate comunicativo $\bullet 73$ del Estado Nación: el caso de la Ley Televisa}


4. A diferencia de los sondeos públicos que se efectuaron en el Senado de la República en el 2006 sobre la reforma a la radiodifusión nacional que no fueron tomadas en cuenta por la mayoría de los legisladores para analizar y votar la Ley Televisa en la Cámara Alta, pues "tenían la consigna de sus partidos para aprobarla sin modificar ni una sola coma”; en la Suprema Corte de Justicia, se abrió un proceso de consulta plural y objetiva, con las partes a favor, en contra y la opinión de técnicos especializados en la materia, para agregar elementos clarificadores para la toma de decisiones racional y desprejuiciada de los diversos magistrados.

5. Contrariamente a los procedimientos legislativos viciados y corruptos que se practicaron en el Congreso, donde tanto en la Cámara de Diputados como en la Cámara de Senadores, varios legisladores miembros de las Comisiones especializadas de analizar y votar las reforma a las leyes federales de radio y televisión y de telecomunicaciones, fueron simultáneamente juez y parte, pues al mismo tiempo actuaron como legisladores del Congreso y en ese mismo momento también se comportaron como concesionarios de medios electrónicos defendiendo sus intereses empresariales; en la Suprema Corte se actuó con mucha imparcialidad y pulcritud institucional. Así, la Corte aceptó la renuncia del ministro José Ramón Cossío cuando él éticamente expuso públicamente que no debía participar como magistrado en dicho proceso sobre el análisis de la Acción de Inconstitucionalidad por el riesgo que se corría al ser juez y parte, pues en años anteriores él había participado como coautor de algunas fracciones del proyecto de comunicación de una de las fracciones políticas que anteriormente se había discutido en el Senado para intentar reformar la radiodifusión nacional.

6. A diferencia de las posiciones de los legisladores de la Cámara Alta y de la Cámara Baja, del Congreso y del Presidente de la República que en el gobierno anterior de la "transición a la democracia" se sometieron a las presiones que ejerció el poder mediático en tiempos de elecciones federales; la Corte no se dobló ante las fuertes inhibiciones que ejerció el poder mediático para evitar que le cancelaran su propuesta de ley. Esto es, actuó como poder republicano soberano que corrigió los errores cometidos por los otros dos poderes de la República que se subordinaron incondicionalmente al poder mediático salvaje.

7. Paradójicamente el proceso que se practicó en el pleno del Senado de la República en marzo del 2006 al discutir la propuesta de la Ley Televisa, no tomó en cuenta los puntos de vista de los parlamentarios críticos y los postulados de la sociedad civil organizada para modificarla y enriquecerla cumpliendo con su labor de legisladores en la Cámara de origen y se despreció toda esa riqueza,

\section{4- Javier Esteinou Madrid}


aprobándose sin cambiarle una sola coma. En cambio durante la discusión por parte de la Suprema Corte de Justicia de la Nación siempre se tomó en cuenta los argumentos contrarios de los magistrados para llegar a una decisión de consenso entre los 9 ministros. Así, el procedimiento de la Suprema Corte siempre partió de una tesis abierta a la discusión pública que expuso el ministro ponente elegido, Aguirre Anguiano, y después cada uno de los magistrados restantes expresaron, con toda libertad, firmeza y pluralidad sus argumentos de fondo, para discutir entre si los razonamientos a favor y en contra.

8. Finalmente, a diferencia del proceso de comunicación institucional que se realiza cotidianamente en la Cámara Baja y Alta del Congreso, donde los legisladores cuando se dirigen desde la máxima tribuna política a sus compañeros de partidos y al resto de la nación para fijar sus posiciones y propuestas partidistas, los demás miembros del Congreso no los escuchan, no asisten a las sesiones, se paran a "cabildear", abandonan los recintos parlamentarios, realizan "grilla politica" de curul en curul, se duermen en sus butacas, hablan por teléfono celular, no abordan todos los aspectos planteados en las minutas, no se respetan entre sí, no alcanzan a formar quórum para efectuar diversas reuniones, se insultan hasta llegar a los golpes, etc; la Suprema Corte de Justicia dio al país un ejemplo de comunicación plural de alta civilidad institucional al demostrar como se pueden abordar los grandes problemas de la agenda pública nacional con seriedad, pluralidad y profunda discusión argumentada, pero en un ambiente de exteriorización respetuosa, de análisis severo, de discusión de principios y de responsabilidad profesional.

Por todos estas razones, el comportamiento de la Suprema Corte de Justicia ante la Acción de Inconstitucionalidad sobre la Ley Televisa fue tan relevante que además de cumplir su trabajo profesional especializado como institución republicana soberana, aportó a la cultura nacional un ejemplo de alta civilidad elemental en el ejercicio de su responsabilidad como poder público, que es necesario que los otros dos poderes de la República lo sigan para rescatar urgentemente al Estado nación de la crisis de aguda rectoría y de representatividad orgánica en la que se encuentra sumergido y atorado al iniciar el siglo Xxi en México.

GaNANCIAS históRICAS DE LA RESOlUCIÓN

DE LA SUPREMA CORTE DE JUSTICIA DE LA NACIÓN

El comportamiento responsable que sostuvo la Suprema Corte de Justicia de la Nación como poder republicano ante la demanda de inconstitucionalidad de la

\author{
La Suprema Corte de Justicia y el rescate comunicativo $\bullet 75$ \\ del Estado Nación: el caso de la Ley Televisa
}


Ley Televisa en el terreno comunicativo, produjeron, entre otras, las siguientes 12 ganancias históricas para la sociedad mexicana:

1. Se puso fin a los tiempos de la Ley Televisa que desde su aprobación por el Congreso de la Unión y su publicación por la Presidencia de la República, en el 2006, se aplicaron sus postulados durante más de un año en nuestro país creando un ambiente de grave inconstitucionalidad, desigualdad, concentración, impunidad, corrupción y desconocimiento de los derechos comunicativos básicos de la población demandados durante varias décadas por la sociedad civil; y se rescataron las bases jurídicas mínimas para crear los tiempos del Estado de Derecho Comunicativo al ubicarse los principios del pacto nacional concretizados en la Carta Magna por encima de los intereses particulares de los poderes fácticos informativos.

2. En comparación con la actuación desleal y antitética del Poder Legislativo y del Poder Judicial ante la reforma a la radiodifusión en ańos anteriores; en el año 2007 se tuvo una Suprema Corte valiente, independiente, e imparcial que actuó sabiamente como árbitro fiel en base al marco de los mandatos elementales de la Constitución del 1917. Aunque dicha masa de postulados constitucionales fueron muy limitados, frágiles, incompletos $\mathrm{y}$ viejos para las necesidades de la sociedad de principios del siglo XXI en México, en última instancia, fue el único marco civilizatorio aprobado con mayor consenso por las comunidades nacionales para convivir pacíficamente y con equilibrio en los tiempos de la modernidad mexicana.

3. Mientras que la actuación del Congreso y del poder presidencial en el sexenio anterior fomentaron en el ámbito informativo la existencia del Estado Padrastro Comunicativo ${ }^{I}$ que se distinguió por la no defensa del

${ }^{1}$ El concepto padrastro comunicativo lo tomamos de aquel fenómeno psíquico afectivo de exclusión que se presenta en las familias que después de experimentar una fractura o divorcio en su integración, donde la figura masculina fundacional es desplazada y para entrar en un nuevo proceso sistémico de reconstrucción emocional del conjunto, aceptan la introducción de una nueva presencia masculina externa a la estructura emocional originaria de la familia para ocupar la dirección de la célula grupal. En esta dinámica la nueva autoridad paternal se vuelve disfuncional para el conjunto de sus miembros, pues el nuevo elemento incorporado no quiere, no trata bien, no cuida, no protege a los hijos preexistentes de la familia anterior, etc; sino al contrario entra en conflicto con ellos, los margina, los abandona, les niega sus derechos elementales, los explota y hasta abusa de ellos, ya que no se siente comprometido con éstos por

76- Javier Esteinou Madrid 
patrimonio comunicativo de la sociedad y de las garantías culturales mínimas de los habitantes; la Suprema Corte de la Justicia rescató las bases constitucionales para recobrar al Estado Nación en el terreno informativo para defender a los individuos y otorgarles sus derechos comunicativos fundamentales como ciudadanos. Así podemos decir que la acción de la Corte recobró la médula comunicativa del Estado Nación mexicano de las garras del Estado Padrastro que lo tuvo secuestrado y olvidado durante varias décadas a través de la imposición de los intereses comunicativos particulares de los grandes monopolios de la radiodifusión sobre los requerimientos informativos mínimos de la sociedad mexicana.

4. Para el futuro comunicativo en México el ejemplo de comportamiento soberano de la Suprema Corte de Justicia, dejó activada una rigurosa dinámica de división plural entre los 3 poderes republicanos de nuestro Estado nación que permitirá que, mediante recursos de inconstitucionalidad que plantee la sociedad ante los tribunales correspondientes, las responsabilidades o acciones que no realicen correctamente el Poder Legislativo o el Poder Ejecutivo en el terreno informativo o cultural, éstas podrán ser impugnadas y corregidas por el Poder Judicial de la Federación.

5. La Corte revindicó en base a los principios constitucionales la propiedad soberana del Estado sobre el espectro radioeléctrico, como patrimonio estratégico e inalienable de la nación, que es la infraestructura radioeléctrica moderna, a través de la cual, la sociedad conoce, interactúa, y se organiza simbólicamente cotidianamente para comunicarse y realizar su vida diaria, vía las tecnologías de información colectivas.

6. Las reflexiones y discusiones de la Suprema Corte de Justicia de la Nación a partir de los fundamentos constitucionales le dejaron a la sociedad mexicana una mina filosófica y conceptual muy valiosa para reflexionar sobre los cimientos elementales que deben tomarse en cuenta para definir el papel que debe adoptar el Estado ante el proceso de la comunicación y la cultura nacionales. Dicho manantial conceptual debe ser la guía para

responder solamente a sus intereses individuales y no del nuevo núcleo familiar constituido. En este sentido, la connotación de padrastro no contiene un significado positivo, sino negativo para la reconfiguración de una comunidad humana, pues el padrastro se convierte en un elemento desintegrador, negativo y destructivo y no positivo e integrador de los individuos que constituyen ese nuevo grupo social.

La Suprema Corte de Justicia y el rescate comunicativo $\bullet 77$ del Estado Nación: el caso de la Ley Televisa 
reconstruir, a través de una nueva Ley Federal de Comunicación Social, el modelo igualitario y participativo de información que la sociedad mexicana ha demandado durante varias décadas, y no concentrador, desigual, marginador, discresional y voraz que han impuesto las industrias culturales comerciales.

7. Además del dictamen final muy valioso que produjeron los ministros para detener el avance de la Ley Televisa y poner orden conceptual y político en la esfera de la comunicación nacional, éstos aportaron una herencia de jurisprudencia estratégica para el futuro legislativo de las radiocomunicaciones en México que dejó una serie de fundamentos constitucionales básicos infranqueables para trabajar legislativamente en las próximas reformas jurídicas de los medios. A partir de los fundamentos sólidos argumentados por la Suprema Corte, dichos postulados tendrán que respetarse por todos los sectores como diques constitucionales definitivos que ya no podrán volver a rebasarse por los poderes públicos o empresariales en los nuevos intentos de reformas que se efectúen sobre la radiodifusión y las telecomunicaciones nacionales, pues la Corte puso límites claros a las tendencias monopólicas de la comunicación y delimitó claramente el lugar rector que le corresponde al Estado nación en el proceso de construcción moderna de la República comunicativa.

8. La acción de la Corte ubicó el proceso de la reforma del Estado en su camino correcto al evidenciar la necesidad urgente de fortalecer la posición del Estado, la figura histórica de la República y el marco de la Constitución Mexicana por encima de las predilecciones de los apetitos fácticos desregulados de los monopolios masivos de la difusión masiva en México. En este sentido, la reforma del Estado debe colocar el cambio radical de la relación existente entre medios, Estado y sociedad como el centro de la reforma estructural, pues de lo contrario no existirá cambio político profundo para lograr la transición pacífica a la democracia en nuestro país.

9. Se rescató el proyecto de comunicación nacional no desde las posiciones ideológicas de los partidos, las "grillas", los cabildeos, las presiones, las "negociaciones", las plataformas electorales, etc; sino desde el elemental manantial de principios constitucionales que formularon, entre otros, los siguientes aspectos: ¿cuál es el lugar que debe ocupar el interés publico ante el proceso de difusión colectiva?; ¿qué posición le corresponde al Estado nación en el ámbito comunicativo?; ¡cómo ubicar los apetitos 
monopólicos irrefrenables ante los derechos ciudadanos?; ¡cuál es la función de los medios públicos y comunitarios en la construcción de la democracia?; ¿qué condiciones se requieren para que exista equidad comunicativa a principios del milenio?, etcétera.

10.Se destacaron las bases jurídico filosóficas básicas para la construcción, sin extravíos, de un proyecto republicano de comunicación de largo plazo en el país que considere la rectoría del Estado y los principios constitucionales como esencia vertebral del modelo de cultura y de información colectiva nacionales, por encima de la dinámica libertina de los intereses voraces e insaciables de los oligopolios de la difusión, que alcanzaron enormes privilegios y grados de concentración y aún así no quedaron satisfechos. Con ello, quedó asentado para el futuro el marco institucional mínimo para edificar un nuevo modelo de comunicación nacional desde el horizonte del servicio público que permita el avance de la sociedad en su conjunto y no sólo de los monopolios de la cultura electrónica.

11.El veredicto de la Suprema Corte dio un enorme impulso al proceso de transición a la democracia en México, pues respaldó, entre otros, los mecanismos de rectoría comunicacional del Estado; la división efectiva de poderes republicanos; el mandato de la Constitución Mexicana por encima de los intereses de la Mano Invisible del mercado monopólico de la difusión; la apertura de la estructura de comunicación a las condiciones de competencia comunicativa; la introducción de criterios de pluralidad, igualdad y ciudadanización de los procesos comunicativos; fijó los límites constitucionales definitivos a los poderes fácticos, etc, que son condiciones básicas para que se pueda gestar el cambio comunicativo y político pacífico en nuestro país al inicio del nuevo milenio.

12. Finalmente, en el proceso de oposición a la Ley Televisa la academia crítica de la comunicación desempeñó una función muy estratégica, pues con sus análisis sistemáticos sobre el origen, la evolución y las consecuencias de todo el proceso de aprobación de la Ley y de la Acción de Inconstitucionalidad, aportaron muchos elementos analíticos de clarificación e impugnación de dicho proyecto. Después de elaborarse dichas semillas intelectuales críticas en las universidades, centros de reflexión, congresos, seminarios, coloquios, reuniones especiales, etc, éstas se difundieron a través de conferencias, artículos, textos, colaboraciones periodísticas, etc, y paulatinamente, penetraron en el ámbito de la opinión pública, de la

\section{La Suprema Corte de Justicia y el rescate comunicativo $\bullet 79$ del Estado Nación: el caso de la Ley Televisa}


cultura y de la estructura política, creando inicialmente fuertes inquietudes de cambio en los sectores políticos dirigentes, que posteriormente se convirtieron en propuestas jurídicas comunicativas de gobernabilidad opuestas a las iniciativas radiotelevisivas de los monopolios comerciales de la información.

Con la realización de todas estas acciones la Suprema Corte de Justicia rescató constitucionalmente el proyecto comunicativo del Estado nación, y con ello, le regresó a la comunidad una cabeza rectora que la gobierne para atender las principales necesidades comunicativas de la sociedad mexicana y no sólo para resolver las exigencias unilaterales para la expansión de los monopolios mediáticos. Mediante esto, gestó nuevas bases civilizatorias y condiciones políticas fundamentales para construir, a largo plazo, en México una nueva sociedad comunicativa democrática y plural en el siglo XXI.

\section{REFERENCIAS}

\section{Libros, revistas y documentos}

"Acción de inconstitucionalidad promovida por Senadores de la LIx Legislatura del Congreso de la Unión en contra del Congreso a través de las Cámaras de Diputados y de Senadores y del Presidente de los Estados Unidos Mexicanos", (2007), Sesión pública ordinaria del Pleno de la Suprema Corte de Justicia de la Nación, Suprema Corte de Justicia de la Nación, México, D.F, 22 de mayo, versión estenográfica, www.scjn.gob.mx

"Proyecto de resolución 26/2006 sobre la acción de inconstitucionalidad promovida por los senadores integrantes de la quincuagésima novena legislatura del Congreso de la Unión", (2007), Ministro Ponente Sergio Salvador Aguirre Anguiano, H. Suprema Corte de Justicia de la Nación, 59 Legislatura del Congreso de la Unión, México, D.F, 23 de mayo, versión estenográfica, www.scjn.gob.mx

Calleja, A. (2005), "Los cangrejos en el Congreso", Suplemento Especial, en: Revista Etcétera, México, D.F, diciembre, www.etcetera.com.mx

Carriedo, L. M. (2006), "Albazo", en: Revista Etcétera, México, D.F, diciembre, www. etcetera.com.mx

Corral Jurado, J. (2006-A), "El Recurso de Inconstitucionalidad y la Organización de la Sociedad Civil", Discurso en el Zócalo, México, D.F, 23 de abril.

Corral Jurado, J. (2006-B), Javier, Resumen de Acción de Inconstitucionalidad que Promovieron Senadores Contra las Leyes de Federales de Radio y Televisión y de Telecomunicaciones, Dictamen de la Nueva Ley Federal de Radio y Televisión, H. Senado de la República, lix Legislatura, México, D.F, 4 de mayo, www.senadorcorral.org

80 - Javier Esteinou Madrid 
Fernández Christlieb, F. (2005), ¿“Fast track” también en el Senado?, en: Revista Proceso No. 1519, Revista de información y análisis, México, D.F, 11 de diciembre.

Islas Reyes, Laura, (2005), "El momento propicio", Suplemento Especial, en: Revista Etcétera, México, D.F, diciembre, www.etcetera.com.mx

"La irresponsabilidad de la Presidencia", 2005, Editorial, Suplemento Especial, en: Revista Etcétera, México, D.F, diciembre, www.etcetera.com.mx

Mejía Barquera, Fernando, (2005), "Los diputados deben una explicación”, Suplemento Especial, en: Revista Etcétera, México, D.F, diciembre, www.etcetera.com.mx

"Mesa de discusión sobre la radio y televisión y las telecomunicaciones", (2007), Participantes Carlos Bello Hernández, Federico García Luna, Ernesto Piedra y José Benavides, Noticiario Oscar Mario Beteta, Conductor: Oscar Mario Beteta, Radio Fórmula, México, D.F, 23 de mayo.

"Noticiario Hechos, Fuerza Informativa Azteca”, (2007), Conductor: Javier Alatorre, Televisión Azteca, México, D.F, 23 de mayo.

"Noticiero con Joaquín López Dóriga", (2007), Conductor Joaquín López Dóriga, Televisa, México, D.F, 23 de mayo.

“Organismos Autónomos fundamentales para la democracia”, en: Revista Vértigo No. 322, Año VII, México 20 de mayo del 2007, www.revistavertigo.com.

Trejo Delarbre, R. (2005), "En siete minutos”, Suplemento Especial, en: Revista Etcétera, México, D.F, diciembre, www.etcetera.com.mx

Yuste, J. Sigilo legislativo, Suplemento Especial, Revista Etcétera, México, D.F, diciembre del 2005, paginas IV y V, www.etcetera.com.mx.

Zoraida Vázquez, J. (2006), "De la Independencia a la consolidación de la República”, en: Nueva Historia Minima de México, Editorial El Colegio de México, Autores Varios (Pablo Escalante Monzalbo, Bernardo García Martínez, Luis Jáuregui, Josefina Zoraida Vázquez, Elisa Speckman Guerra, Javier Garciadiego y Luis Aboites Aguilar), Tercera reimpresión, México, D.F.

Hemerografía

"Acuerdan senadores del PAN hacer observaciones a la ley de medios", (2006), Periódico El Universal, México, D.F, 26 de enero.

“Acepta Corte controversia acerca de Ley de Radio y Televisión”, (2006), Periódico El Economista, México, D.F, 10 de mayo.

"Acuerdan senadores del PAN hacer observaciones a ley de medios", (2006), Periódico El Universal, México, D.F, 26 de enero.

“Admite la Corte impugnación a las reformas de ley de radio y televisión), (2006), Periódico Milenio Diario, México, D.F, 10 de mayo.

"Analizan ir a la Corte para corregir omisiones", (2006), Periódico El Universal, México, D.F, 30 de marzo.

"Analizarán el jueves avance de controversia contra ley de medios", (2006), Periódico El Universal, México, D.F, 26 de abril.

“Apoyan 110 diputados para ley en la Corte”, (2006), Periódico Reforma, México, D.F, 30 de abril.

La Suprema Corte de Justicia y el rescate comunicativo $\bullet 8$ I del Estado Nación: el caso de la Ley Televisa 
"Apoyan $40 \%$ de los senadores que se declare inconstitucional la Ley Televisa", (2006), Periódico La Jornada, México, D.F, 5 de mayo.

"Aprueba Senado sin cambios, reforma a ley de medios", (2006), El Universal, México, D.F, 31 de marzo.

"Buscan anular Ley Televisa”, (2006), Periódico Reforma, México, D.F, 4 de mayo.

"Buscan apoyo de gobiernos locales para el juicio en la Corte", (2006), Periódico El Universal, México, D.F, 7 de mayo del.

"Cirugía mayor a ley de medios, empujan senadores", (2006), Periódico El Universal, México, D.F, 24 de febrero.

Corral Jurado, Javier, "Estaba Cantada", (2006-C), Periódico El Universal, México, D.F, 18 de abril.

Corral Jurado, Javier, "La opción moral", (2006-D), Periódico El Universal, México, D.F, 9 de mayo.

Corral, Jurado, Javier, "Nueva simulación", (2006-E), Periódico El Universal, México, D.F, 28 de febrero.

Cremoux, Raúl, "Complicidad silenciosa", (2006), Periódico El Universal, México, D.F, 31 de marzo.

"Defenderán controversia ante ministros", (2006), Periódico El Universal, México, D.F, 9 de mayo.

"El Estado se rindió ante las televisoras", (2006), Invertia, Infosel Financiero, México, D.F, 1 de marzo.

"El freno de la Corte a la Ley Televisa podría tardar hasta seis meses: Vicencio", (2006), Periódico La Jornada, México, D.F, 7 mayo.

"En manos de la Corte, futuro de la Ley de Radio y TV", (2006), Periódico El universal, México, D.F, 4 de mayo.

"Encalla Ley Televisa en antesala de Corte", (2006), Periódico Excelsior, México, D.F, 16 de mayo.

"Enfilan a la Corte la ley de medios", (2006), Periódico Reforma, México, D.F, 29 de marzo.

"Explicarán alegatos en la Corte contra Ley de medios, Periódico", (2006), El Universal, México, D.F, 8 de mayo.

"Exponen en ley de medios 21 fallas a la Constitución", (2006), Periódico El universal, México, D.F, 6 de mayo.

"Expresan en Bienal de Radio rechazo a la Ley de Medios", (2006), Periódico El Universal, México, D.F, 16 de mayo.

"Foros de información, Periódico", (2006), La Jornada, México, D.F, 10 de mayo.

"La Corte da entrada a la controversia de los senadores contra la Ley Televisa", (2006), Periódico La Jornada, México, D.F, 10 de mayo.

"La Corte recibe recurso contra la ley de radio y televisión", (2006), Periódico El Universal, México, D.F, 5 de mayo.

"Legisladores confían en una victoria jurídica", (2006), Periódico La Jornada, México, D.F, 10 de mayo.

82 - Javier Esteinou Madrid 
“Ley Televisa. Acepta Gómez error al apoyar minuta; irá a Corte”, (2006), Invertia, Infosel Financiero, México, D.F, 28 de marzo, http://www. invertia.com.

"Los senadores opositores a la Ley Televisa presentarán hoy inconformidad en la Corte", (2006), Periódico La Jornada, México, D.F, 4 de mayo.

"Ni una coma, fue la consigna", (2006), El Universal, México, D.F, 31 de marzo.

"Pide Corral a Senado no dejarse amedrentar por TV", (2006), Invertia, Infosel Financiero, México, D.F, 28 de marzo.

"PRD Llama al Senado a no aprobar reforma a medios", (2006), Periódico El Universal, 23 de enero.

"Presentan 47 senadores acción de inconstitucionalidad contra Ley de Radio y TV", (2006), Periódico Milenio Diario, México, D.F, 4 de mayo.

"Presentarán demanda de inconstitucionalidad a la Ley de Radio y T.V", (2006), Periódico El Financiero, México, D.F, 4 de mayo.

"Presentarán recurso contra la ley de radio y televisión”, (2006), Periódico Milenio, México, D.F, 30 de abril.

"Presidencia tiene tiempo de analizar veto, asegura Sauri", (2006), Periódico El Universal, 9 de abril.

"Prevén que Corte declare nulas las reformas", (2006), Periódico El Universal, 27 de abril.

"Queda en manos de la Suprema Corte la ley de medios", (2006), Periódico El Financiero, México, 5 de mayo.

"Radio y televisión ante la Corte”, (2006), Periódico El Universal, México, D.F, 17 de abril.

"Revisan ministros Ley Televisa", (2006), Periódico Reforma, México, D.F. 10 de mayo.

"Senadores afinan recursos contra ley de medios", (2006), Periódico El Universal, México, D.F, 17 de abril.

"Senadores del PAN discuten cambios a la ley de radio y televisión, Periódico El Universal, México, D.F, 26 de enero.

"Senadores hablaron con Azuela, Periódico El Universal, México, D.F, 10 de mayo.

"Senadores logran votos necesarios para controversia, Periódico El Universal, México, D.F, 11 de abril.

"Senadores presentan hoy controversia constitucional contra ley de radio y tv", (2006), Periódico El Universal, México, D.F, 4 de mayo.

"Sociedad civil exige a Corte invalidar las reformas", (2006), Periódico El Universal, México, D.F, 7 de mayo.

"Urgen fallo para la Ley Televisa”, (2006), Periódico Excélsior, México, D.F, 8 de mayo.

"Van senadores a la SCJ", (2006), Periódico La Jornada, México, D.F, 1 de mayo, www.senadorcorral.org.

"Ven 21 violaciones a la Carta Magna por ley de medios", (2006), Periódico El Universal, México, D.F, 6 de mayo.

La Suprema Corte de Justicia y el rescate comunicativo $\bullet 83$ del Estado Nación: el caso de la Ley Televisa 